\title{
DIREITO INTEGRAL À SAÚDE: ESTUDO COM SUJEITOS ENVOLVIDOS EM ACIDENTES DE TRÂNSITO SOB A PERCEPÇÃO dO SERVIÇO SOCIAL
}

\author{
INTEGRAL HEALTH RIGHTS: STUDY WITH SUBJECTS INVOLVED IN TRANSIT \\ ACCIDENTS UNDER THE PERCEPTION OF SOCIAL WORK
}

\author{
Marla Pedroso Marth ${ }^{1}$ \\ Erika Scheeren Soares ${ }^{2}$
}

\section{RESUMO}

Este estudo teve como objetivos identificar o perfil dos pacientes atendidos em um serviço de emergência em decorrência de acidente de trânsito, verificar as implicações socioeconômicas para os envolvidos e as intervenções do Serviço Social para esse público. A metodologia adotada foi qualitativa, com dados quantitativos complementares. Identificou-se que a maioria dos envolvidos são jovens, do sexo masculino, com idade média de 28 anos, de baixa escolaridade, ocupantes de motocicletas e com dificuldades financeiras e alterações no contexto familiar em decorrência do acidente. Concluiu-se a importância das políticas públicas de articulação entre os serviços para a proteção social dos envolvidos e a relevância da intervenção do Serviço Social com vistas a proporcionar um atendimento integral e contribuir para o acesso aos direitos sociais dos sujeitos envolvidos.

PALAVRAS-CHAVE: Serviço Social. Direitos Sociais. Acidente de Trânsito. Saúde Integral.

\section{ABSTRACT}

This study aimed to identify the profile of patients seen in an emergency service due to traffic accident; To verify the socioeconomic implications for those involved and; To verify the interventions of the social work for this public. The methodology adopted was qualitative, with

\footnotetext{
${ }^{1}$ Assistente Social, com graduação em Serviço Social pela UNISC, integrante do Programa de PósGraduação em Residência Multiprofissional Integrada em Saúde, com ênfase Urgência, Emergência e Intensivismo da UNISC/ Hospital Santa Cruz Sul/RS. Telefone: (51) 9 9893-5400. E-mail: marlapmarth@gmail.com.

${ }^{2}$ Graduação em Serviço Social pela PUCRS; Mestrado e Doutorado em Serviço Social pela PUCRS. Docente do Curso de Serviço Social da UNISC e Tutora do Serviço Social no Programa de Pós Graduação em Residência Multiprofissional Integrada em Saúde - ênfase Urgência, Emergência e Intensivismo da UNISC/Hospital Santa Cruz/RS. E-mail: erika@ unisc.br.
} 
complementary quantitative data. The interview was conducted in two stages, with different forms. It was identified that, the majority of the involved ones are young, male, with average age of 28 years, of low schooling, occupants of motorcycles and, with financial difficulties and alterations in the familiar context as a result of the accident. It was concluded the importance of the public policies articulation between the services for the social protection of those involved and the relevance of the intervention of the social work in order to provide integral care and contribute to the access to the social rights of the individuals involved.

KEYWORDS: Social Work. Social rights. Traffic-accidents. Integrality Cheers.

\section{INTRODUÇÃO}

Os municípios de abrangência da $13^{\circ}$ Coordenadoria Regional de Saúde do Rio Grande do Sul contam com um serviço situado no município de Santa Cruz do Sul que é referência em Alta Complexidade no atendimento a Traumatologia. Com esse respaldo, o referido serviço juntamente com a Universidade local, mantém um Programa de PósGraduação em Residência Multiprofissional em Saúde, com ênfase em Urgência, Emergência e Intensivismo, financiado pelo Ministério da Saúde. Esse Programa contempla oito áreas da saúde, sendo o Serviço Social uma delas.

Os sujeitos envolvidos em acidentes de trânsito compõe um número relevante dos atendimentos no referido serviço custeado pelo Sistema Único de Saúde - SUS. No entanto, verificou-se através das revisões de literatura, uma ausência de pesquisas sobre a temática, principalmente no que tange a área do Serviço Social. Este foi um dos principais fatores que contribuíram para eleger essa temática como foco de investigação. Também, não foi encontrado nenhum estudo semelhante a este realizado no Serviço de Saúde.

Sabe-se que para além do sofrimento físico e psíquico, os acidentes de trânsitos desencadeiam uma série de expressões da questão social até então não vivenciadas pelos sujeitos e seus familiares (ANJOS, 2012), o que sugere a necessidade da intervenção do Serviço Social, juntamente com outros profissionais, com vistas a contribuir para a garantia do direito integral à saúde do indivíduo.

Tendo em vista o aumento significativo dos indicadores de morbidade e mortalidade relacionados aos acidentes de trânsito nos últimos anos, o Ministério da Saúde tem alertado para o impacto negativo destes sobre a saúde da população brasileira, como a perda de anos de vida livres, a redução da expectativa de vida, 
principalmente do público adolescente e jovem, além dos altos custos sociais e econômicos impostos ao sistema de saúde e previdenciário (MARÍN-LEÓN, 2012).

Diante disso, o Poder Público brasileiro tem considerado os índices de acidente de trânsito como um relevante problema de saúde pública. Como se configuram em problemas causados por seres humanos, grande parte dos acidentes de trânsito pode ser previsível e prevenido (PEDEN, 2004), e por isso, essa temática tem sido alvo de "ações de saúde e de educação permanente, voltadas para a vigilância e prevenção das violências e acidentes, das lesões, acidentes e mortes no trânsito" (BRASIL, 2011, p. $4)^{3}$.

Os jovens continuam sendo as vítimas mais vulneráveis no trânsito. A participação das mulheres entre as vítimas de acidentes de trânsito mantém-se em torno dos $20 \%$ ao longo dos anos, mas as mulheres que vieram a óbito na situação de condutora ou motociclista cresceram $66 \%$ de 2010 para $2014^{4}$.

Dessa forma, considerando os determinantes e condicionantes para reabilitação da saúde dos sujeitos envolvidos em acidentes de trânsito e a necessidade de um cuidado integral, este estudo teve três objetivos: o primeiro consistiu em identificar o perfil dos usuários atendidos em um Serviço de Emergência do SUS na cidade de Santa Cruz do Sul em decorrência de acidente de trânsito com posterior internação hospitalar, o segundo, verificar as alterações na rotina e implicações socioeconômicas em decorrência do acidente após três meses da alta hospitalar e o terceiro, verificar as intervenções do assistente social junto aos envolvidos em acidente de trânsito, durante a internação hospitalar.

Compreende-se que os resultados dessa pesquisa têm extrema relevância para o Poder Público, para a sociedade, para o Serviço de Saúde e principalmente para os envolvidos e seus familiares, uma vez que poderão ter acesso a dados que não são divulgados nos meios comuns de comunicação. Além disso, propõe expor o cenário dos sujeitos envolvidos em acidentes de trânsito após a internação hospitalar, o que

\footnotetext{
${ }^{3}$ Acidente de trânsito neste estudo é compreendido como um evento complexo que envolve falhas humanas, dos veículos, além dos fatores desfavoráveis ambientais. Muitas causas destes acidentes envolvem manobras arriscadas no manejo do veículo, uso de álcool e drogas, velocidade excessiva, cansaço, influências climáticas, vias e sinalização inadequadas ou falta de manutenção dos veículos (OLIVEIRA; SOUZA, 2006).

${ }^{4}$ Dados extraídos do site do DETRAN. Disponível em: http://www.detran.rs.gov.br/conteudo/33626/detran-rs-divulga-relatorio-da-acidentalidade-2014--Acesso em 18 jun. de 2015.
}

Serv. Soc. \& Saúde, Campinas, SP v.16, n. 1 (23), p. 99-118, jan./jun. 2017 ISSN 1676-6806 
compreende uma reflexão sobre a necessidade do trabalho em rede para efetivação do direito integral a saúde.

A metodologia deste estudo caracteriza-se como qualitativa com dados quantitativos complementares, de delineamento observacional, descritiva e transversal ${ }^{5}$ (GIL, 2008).

Para a coleta de dados foram realizadas duas entrevistas com formulários distintos: a primeira entrevista ocorreu no período de 01 de novembro de 2015 a 30 de abril de $2016^{6}$, com 34 sujeitos submetidos à internação hospitalar, após atendimento de emergência. A segunda etapa ocorreu em um período de três meses após a data da alta hospitalar; nesta etapa, foram realizadas 25 entrevistas, uma vez que os demais sujeitos da pesquisa não foram localizados.

\section{Perfil socioeconômico dos sujeitos envolvidos, caracterização dos acidentes de trânsito e o processo de produção e reprodução social}

Com relação ao perfil dos sujeitos envolvidos, dos 34 incluídos no estudo, 29 eram do sexo masculino. A média de idade foi de 28 anos, com idade mínima de 18 e máxima de 58 anos. A maioria (29 sujeitos) era domiciliado no município de Santa Cruz do Sul. Sobre a escolaridade, a maior parte (23 sujeitos) declarou ensino médio incompleto, 10 com ensino médio completo e 01 com ensino superior completo.

O baixo nível de escolaridade em sujeitos jovens envolvidos em acidentes de trânsito também foi identificado em estudos dos autores Santos (2008) e Golias (2013). Contudo, não há evidências que relacionem diretamente baixa escolaridade com propensão a acidentes no trânsito. Porém, a inexperiência, a ausência de familiaridade com as leis do trânsito e de habilidade no dirigir, dificuldade em perceber o perigo e resolver os problemas, maior tendência em dirigir com excessiva velocidade e uso de psicoativos antes da condução podem estar relacionados com a elevada frequência de jovens envolvidos em acidente no trânsito (SANTOS 2008; GOLIAS, 2013; CAIXETA, 2010).

\footnotetext{
${ }^{5}$ O presente estudo foi aprovado pelo Comitê de Ética em Pesquisa sob o parecer de $n^{\circ}$ 1.337.708/15.

${ }^{6}$ No referido período, 42 sujeitos envolvidos em acidentes de trânsito foram internados no hospital em questão. Contudo, 08 não correspondiam aos critérios de inclusão do estudo, como: transferência para outro serviço, óbito do sujeito ou demais envolvidos e atendimento por plano de saúde privado.
} 
Sobre o contexto sócio familiar, 24 sujeitos afirmaram estado civil, solteiro, e 30 sujeitos declararam residir com uma ou mais pessoas da família. Referente à situação profissional, 25 sujeitos afirmaram exercer atividade remunerada formal com inscrição no Regime Geral de Previdência Social (RGPS), 08 com atividade informal e 01 não soube informar. A média de renda dos entrevistados foi de $\mathrm{R} \$ 1.400,00$ e a média da renda familiar foi de $\mathrm{R} \$ 2.750,00$. Estes resultados corroboram com os dados encontrados por Anjos (2012) e Santos (2008) no qual a maioria dos entrevistados relatou que estavam inscritos no RGPS com uma renda mensal em média de R\$ 1.200,00.

No que se referem às características do acidente de trânsito, a maioria (29 sujeitos) estava conduzindo motocicleta no momento do acidente. Outros estudos realizados no Brasil, também apontaram que os grupos de maior risco para os acidentes de trânsito são jovens do sexo masculino ocupantes de motocicletas (MARÍN-LEON, 2012; PALU, 2013; ASCARI et. al., 2013).

Vale ressaltar que no Brasil, houve um aumento expressivo da frota de motocicletas. Dados mostram que no conjunto das 15 principais regiões metropolitanas o crescimento foi de $315 \%$, o que corresponde a um acréscimo absoluto de 3,9 milhões entre 2001 e 2012 (RODRIGUES, 2013).

Esse significativo crescimento está associado aos relevantes incentivos fiscais por parte do Poder Público, para com a indústria de motocicletas, ocasionando o seu baixo custo de aquisição e manutenção, além de ser uma possibilidade de deslocamento rápido, bem como um importante instrumento de trabalho (GOLIAS et al., 2013). No entanto, a motocicleta expõe seus condutores a uma maior vulnerabilidade física em relação a outros veículos automotores.

Contudo, a indústria de motocicletas sempre evitou discutir a insegurança do seu produto, bem como procurou afastá-lo de uma imagem negativa (VASCONCELOS, 2008). Essa análise remete a afirmação de Marx (1988, p. 206), que "o capital não tem a menor consideração pela saúde e duração de vida do trabalhador, a não ser quando é coagido pela sociedade a ter consideração". Reforça ainda que a produção capitalista não apenas atrofia a força de trabalho, a qual é roubada de suas condições normais, morais e físicas, de desenvolvimento, ela produz a exaustão prematura e o aniquilamento da própria força de trabalho. 
Destaca-se ainda, sobre os resultados desse estudo, que dos 34 sujeitos apenas 12 declararam que estavam no percurso para o trabalho, sendo a maioria dos acidentes com ocorrência no sábado e no domingo.

Diante disso, compreende-se que "o processo de produção e reprodução da vida através do trabalho é para Marx, a atividade humana básica, a partir da qual se constitui a história dos homens...” (QUINTANEIRO et al, 2002, p. 33), assim, não há como dissociar o trabalho das demais objetividades, uma vez que o ser social se constrói através do trabalho.

Portanto, no contexto do acidente de trânsito, percebe-se que há uma ausência de consciência sobre a necessidade de cuidado com o que é uso coletivo, principalmente por parte da indústria, o que é desencadeado justamente pela expansão do capitalismo que tende à corrosão do caráter dos indivíduos, sobretudo das qualidades de caráter que ligam os seres humanos uns aos outros e dão a cada um deles um senso de solidariedade e identidade (ANTUNES; POCHMANN, 2007).

\section{Implicações no contexto sociofamiliar e do trabalho em sujeitos envolvidos em acidentes de trânsito e acesso aos direitos sociais}

Com o intuito de verificar as implicações sociais para o sujeito envolvido em acidente de trânsito, após três meses da data de alta hospitalar, foram localizados 25 sujeitos para realização da entrevista.

No que se referem às implicações no contexto familiar, destes, quase todos (24 sujeitos) afirmaram que após o acidente de trânsito precisaram do auxílio de outra pessoa para realização das atividades diárias, bem como referenciaram a figura da mulher, mãe e/ou esposa como a principal pessoa responsabilizada por esse cuidado. Este fato pode estar associado à questão cultural, tendo em vista a consolidação de uma sociedade de base patriarcal, na qual se instaurou uma hierarquia entre os sexos, com dominação masculina e subordinação feminina (GAVILANES; AGUIAR, 2010).

Nessa perspectiva, os homens são vistos como os protagonistas do cenário econômico e político, e as mulheres, incumbidas pela esfera doméstica, "inadequadas à esfera pública". Assim, historicamente, coube à mulher as atividades ligadas ao 
cuidado, justificadas por qualidades que constituem a "natureza da mulher" (FERREIRA, 2014).

$\mathrm{Na}$ atualidade, porém, com a maior participação das mulheres nos espaços políticos, o modelo de família pautado no patriarcado começou a sofrer modificações. Como fruto dessa nova configuração econômica, a mulher passou a ter condições de se posicionar melhor dentro e fora de casa, e assim as relações de submissão e poder começaram a sofrer modificações (ROUDINESCO, 2003). No entanto, 08 sujeitos responderam que uma integrante da família do sexo feminino (mãe ou companheira), deixou seu espaço de trabalho, abdicando de sua renda, devido à necessidade de acompanhamento diário após o acidente de trânsito.

Ademais, destaca-se que a maioria (25) dos entrevistados declarou inscrição ativa no RGPS, o que possibilitou o afastamento das atividades laborais com direito a um benefício social ${ }^{7}$. Contudo, todos os entrevistados mencionaram uma diminuição na renda mensal, o que necessitou a solicitação de empréstimos financeiros, recorridos principalmente a familiares.

Destarte, compreende-se que a ocorrência de um acidente de trânsito implica sobremaneira no contexto sociofamiliar dos sujeitos envolvidos. Dessa forma, o modo como a família consegue suprir as suas necessidades e os processos de alienação social, política e econômica a que são submetidas, está relacionado diretamente com sua condição de classe trabalhadora (SIERRA; VELOSO, 2015).

No que tange aos direitos sociais, destaca-se que os envolvidos em acidentes de trânsito têm direito ao Seguro Obrigatório de Veículos Automotores de Via Terrestre DPVAT $^{8}$. Apesar de sua relevância, esta modalidade de seguro não é de conhecimento da maior parte da população, e não lhe são mostradas as possibilidades que tem de como realmente exigir a indenização a que lhe é de direito (MARTINS, 2009).

\footnotetext{
${ }^{7}$ A Previdência Social é um direito constitucional, de caráter contributivo que garante aos seus segurados renda não inferior ao um salário mínimo ao trabalhador e sua família em situações de doença, invalidez, morte, idade avançada, entre outras. Dentre os contribuintes, encontram-se empregadores, empregados assalariados, empregados domésticos, contribuintes individuais e trabalhadores rurais (BRASIL, 1991).

${ }^{8}$ Lei 6.194 de 19 de dezembro de 1974. Este se configura em seguro de caráter social que indeniza pessoas envolvidas em acidentes de trânsito, sem apuração de culpa, seja motorista, passageiro ou pedestre. O DPVAT oferece coberturas para três naturezas de danos: morte, invalidez permanente e reembolso de despesas médicas e hospitalares e pode ser solicitado pelo próprio usuário.
} 
Este fato ficou explícito neste estudo, uma vez que dos 25 sujeitos, apenas 04 solicitaram o seguro por conta própria. O restante terceirizou a solicitação para uma empresa especializada, o que custou de 20 a $30 \%$ do valor total do seguro.

Para além das despesas convencionais, cabe ressaltar que todos os entrevistados relataram a necessidade de medicamentos, curativos, algum aparelho ortopédico, sessões de fisioterapia e psicoterapia após a alta hospitalar. Alguns com a necessidade de outras cirurgias corretivas devido à gravidade do trauma.

Para tanto, 19 sujeitos relataram residir em área de cobertura da Estratégia Saúde da Família - $\mathrm{ESF}^{9}$, o que foi primordial para continuidade no tratamento, principalmente no que tange aos curativos e agendamento de consultas/cirurgias posteriores.

Neste aspecto, as maiores dificuldades relatadas pelos entrevistados foram referentes ao acompanhamento fisioterapêutico, uma vez que as sessões de fisioterapia pelo SUS eram limitadas no município, sendo necessário o custeamento do restante pelo usuário. Um dos entrevistados afirmou: "Só consegui pelo SUS metade do que o médico receitou o resto eu tive que pagar essas coisas não da para deixar assim" (ENTREVISTADO 7) e outro afirmou "Tive que pagar porque tava demorando muito" (ENTREVISTADO 15).

Além disso, 20 sujeitos afirmaram a necessidade de algum aparelho ortopédico (muletas, cadeira de rodas, entre outros) temporariamente ou permanentemente. No entanto, nenhum solicitou via SUS e, a maioria relatou desconhecimento dessa possibilidade, conforme verbalizou um dos entrevistados "Eu nem sabia que isso tinha pelo SUS, o cara do DPVAT me levou as muletas quando eu tava no hospital" (ENTREVISTADO 22).

Assim, observa-se que a aquisição dos materiais ortopédicos se deu por meio de doações ou empréstimos e não via efetivação de direitos sociais. Nessa afirmação, fica evidente que as empresas de seguro DPVAT vão ao encontro de seus clientes e oferecem seus serviços ainda no processo de hospitalização.

\footnotetext{
${ }^{9}$ Integra a Política Nacional de Atenção Básica (implantada em 1994 como Programa Saúde da Família). Configura-se como uma estratégia de reorientação do modelo assistencial, baseada nos princípios a territorialização, vinculação com a população, integralidade na atenção, trabalho em equipe com enfoque multidisciplinar, promoção da saúde com fortalecimento das ações intersetoriais e estímulo a participação da comunidade (SOUZA, 2000).
} 
Ademais, cabe destacar que a maioria dos sujeitos está vinculada ao RGPS, este que tem como um de seus pilares a habilitação e reabilitação profissional e social que compreende,

Proporcionar ao beneficiário incapacitado parcial ou totalmente para o trabalho os meios para a (re) educação e de (re) adaptação profissional e social indicados para participar do mercado de trabalho e do contexto em que vive [...]. A reabilitação profissional compreende: a) o fornecimento de aparelho de prótese, órtese e instrumentos de auxílio para locomoção quando a perda ou redução da capacidade funcional puder ser atenuada por seu uso e dos equipamentos necessários à habilitação e reabilitação social e profissional [...] (BRASIL, 1991, p. 31).

Desta forma, percebem-se inúmeros aspectos que não estão sendo efetivados pelas políticas públicas, ou seja, há uma distância entre a legislação vigente e o acesso desses direitos na realidade, tornando-se evidente a violação de direitos.

No entanto, considerando o direito como o resultado da estabilização do conflito de interesses divergentes e, sobretudo, o alicerce da ordem política e social, é inegável que as transformações recentes têm demonstrado a (des) responsabilização do Estado com a reprodução social, afetando com isso as condições de vida das famílias (SIERRA; VELOSO, 2015).

Assim, compreende-se a vulnerabilidade em que se encontra a classe trabalhadora, uma vez que mesmo com tantas conquistas, no que tange a proteção social, as estratégias para alcançar um Estado mínimo tem ganhado cada vez mais espaço na agenda dos governantes, da mídia e principalmente para os próprios trabalhadores que são cooptados diariamente por esse discurso político.

E, para além das implicações no contexto social, já referidas, Cavalcante (2009) aponta para os transtornos de estresse pós-traumático e os denomina de impactos invisíveis dos acidentes de trânsito. Assim, classifica as vítimas sobreviventes de acidentes de trânsito em: a) sobreviventes primárias - as vítimas submetidas ao nível máximo de exposição; b) sobreviventes secundários - os familiares próximos das vítimas; c) vítimas de terceiro grau - os profissionais que atuam na comunidade e no socorro às vítimas.

No presente estudo apenas 01 sujeito relatou a necessidade de acompanhamento psicológico após internação hospitalar, conforme afirmação: “Eu tô tendo psicóloga uma vez na semana, mas estou pagando com doações que recebi dos amigos e alunos 
da escola que eu trabalho" (ENTREVISTADO 3). Não ficou evidenciado se esta necessidade foi sinalizada pelo profissional de referência ainda na atenção hospitalar ou por iniciativa própria.

No entanto, compreende-se que as necessidades de saúde possuem uma expressão múltipla - social, psicológica, biológica e cultural e, que tanto o conhecimento quanto as intervenções sobre o processo saúde-doença fazem parte de um intenso e complexo processo de múltiplas determinações. Dessa forma, é indispensável a atuação das diversas categorias profissionais que compõem a área da saúde, uma vez que possuem saberes e responsabilidades diferenciadas que, articuladas, são fundamentais para a efetivação da integralidade em saúde.

É importante destacar que as subjetividades do sujeito não são objeto de trabalho do assistente social, contudo, elas são manifestadas durante a intervenção, seja ela individual ou coletiva, justamente porque a subjetividade é inerente a qualquer pessoa que esteja em situação de ameaça ou violação de algum direito social (NICÁCIO, 2005).

Dessa forma, considerando que "um paciente não se reduz a uma lesão que no momento lhe causa sofrimento. Não se reduz a um corpo com possíveis lesões ainda silenciosas, escondidas à espera de um olhar astuto que as descubra" (MATTOS, 2009, p. 64) e com base nos resultados já referidos, evidencia-se a necessidade de discutir se de fato a integralidade à saúde tem sido um princípio orientador das práticas, bem como um orientador da organização do trabalho em saúde. A integralidade implica uma recusa ao reducionismo, uma recusa à objetivação dos sujeitos e talvez uma afirmação da abertura para o diálogo (MATTOS, 2009).

Ademais, tendo em vista o aspecto biopsicossocial dos sujeitos, é de extrema relevância a efetivação de uma abordagem multiprofissional, bem como se faz necessário atentar-se para que o planejamento da alta do paciente esteja inserido no projeto terapêutico singular com vistas ao fortalecimento do trabalho em rede, ambos imprescindíveis para a efetivação da integralidade em saúde. 


\section{A importância do Serviço Social para a efetivação da saúde integral}

A partir da Constituição Federal de 1988, foram implementadas uma série de políticas públicas com vistas à garantia de direitos do cidadão e responsabilidade do Estado em relação à provisão dos serviços e benefícios, buscando corrigir históricas injustiças sociais acumuladas secularmente (BRAVO, 2001).

No contexto social do sujeito envolvido em acidente de trânsito, em que o mesmo fica impossibilitado temporariamente ou não de buscar estratégias para sua sobrevivência, as políticas públicas de Saúde e de Previdência Social, como já mencionadas ao longo do texto, tornam-se imprescindíveis para efetivação da cidadania e proteção social.

A política pública de saúde é fundamentada em princípios e diretrizes de descentralização, universalidade, integralidade, participação da comunidade, equidade, igualdade de preservação da autonomia. Nesta perspectiva, compreende-se que,

Os níveis de saúde expressam a organização social e econômica do País, tendo a saúde como determinantes e condicionantes, entre outros, a alimentação, a moradia, o saneamento básico, o meio ambiente, o trabalho, a renda, a educação, a atividade física, o transporte, o lazer e o acesso aos bens e serviços essenciais (BRASIL, 1990, p. 1).

Diante disso, embora os envolvidos em acidentes de trânsito tenham relatado algumas dificuldades no acesso a serviços e recursos de saúde após a hospitalização, cabe enaltecer a importância de um serviço de saúde público universal, principalmente no que tange ao atendimento imediato.

Assim, destaca-se o pré-atendimento, no qual tiveram acesso ao atendimento imediato através do Serviço de Atendimento Móvel de Urgência - SAMU amparado pela Política de Urgência e Emergência, bem como a hospitalização, que compreende cirurgias, terapia intensiva, entre outros recursos tecnológicos imprescindíveis para a reabilitação da saúde.

Consoante, a Política Previdenciária contempla alguns preceitos como: a universalidade da cobertura e do atendimento; a uniformidade dos benefícios e serviços concedidos à população urbana e rural; a seletividade e a distributividade na prestação dos direitos e a participação da sociedade na gestão descentralizada da administração através da participação dos trabalhadores, dos empregadores e dos aposentados (UGINO; MARQUES, 2012). 
A filiação dos trabalhadores ao RGPS é um direito social de extrema relevância. Como demonstrado, a maior parte dos sujeitos envolvidos em acidentes de trânsito precisaram de afastamento de suas atividades laborais, assim, receberem o benefício que lhes é de direito para suprimento de suas necessidades básicas.

Nessa perspectiva, mesmo diante de muitas limitações e desafios, o trabalho desenvolvido pelo assistente social tanto na formulação, gestão como na execução da política social é, indiscutivelmente, peça importante para o processo de institucionalização das políticas públicas, para a afirmação da lógica da garantia dos direitos sociais (MIOTO; NOGUEIRA, 2013).

Assim, as políticas públicas estão intrinsecamente ligadas com o trabalho desenvolvido pelo assistente social desde o início da profissão no Brasil. Além disso, Netto (1992) se refere ao profissional, que além de planejador de políticas, também atua como "executor terminal", operando serviços, programas e projetos implementados por meio de políticas públicas.

No presente estudo, os sujeitos foram questionados sobre a intervenção de um profissional assistente social durante a internação hospitalar. Dos 25 sujeitos entrevistados na segunda etapa da pesquisa, a grande maioria (18) respondeu que não houve nenhum contato com o referido profissional; 02 responderam que não lembram e 04 associaram o profissional à solicitação de refeição para acompanhante e orientação de não fazer muitos exercícios físicos. Após a alta hospitalar, também não houve acompanhamento de nenhum assistente social segundo os entrevistados.

Este resultado difere do estudo de Anjos (2012), no qual o assistente social é lembrado por informar sobre direitos sociais do sujeito e acolher os familiares.

Cabe destacar que, mesmo sendo um serviço de referência para trauma, a instituição conta com apenas dois profissionais do Serviço Social, com horários distintos, para atender um hospital com capacidade de 234 leitos, o que inclui maternidade, pediatria, unidades de internação e unidades de terapia intensiva adulto e neopediátrica.

Os dois assistentes sociais integrantes do Programa de Residência Multiprofissional têm atividades distintas, e se concentram, no primeiro ano, em outro Serviço da Rede de Saúde e, no segundo, especificamente no Serviço de Urgência e Emergência.

Serv. Soc. \& Saúde, Campinas, SP v.16, n. 1 (23), p. 99-118, jan./jun. 2017 ISSN 1676-6806 
Dessa forma, aspectos como altas demandas para poucos profissionais e precarização do trabalho interferem e limitam o trabalho da assistente social, que apesar de estar baseado em seu próprio projeto de trabalho, também está dependente das condições impostas pelo empregador.

Iamamoto (2010, p. 416) reforça que,

Verifica-se uma tensão entre projeto profissional, que firma o assistente social como um ser prático-social dotado de liberdade e teleologia, capaz de realizar projeções e buscar implementá-las na vida social; e a condição de trabalhador assalariado, cujas ações são submetidas ao poder dos empregadores e determinadas por condições externas aos indivíduos singulares, às quais são socialmente forjados a subordinar-se, ainda que coletivamente possam rebelar-se.

Assim, as condições de trabalho interferem sobremaneira no serviço prestado, o que ficou evidente neste estudo, uma vez que há um desconhecimento do usuário do serviço quanto ao trabalho e relevância do assistente social. Esse que partilhando o trabalho com os outros profissionais dispõe de ângulos particulares na interpretação dos mesmos processos sociais e de uma competência distinta para a realização das ações profissionais (IAMAMOTO, 2002).

Em documento elaborado pelo Conselho Federal de Serviço Social - CFESS, intitulado, "Parâmetros para a atuação de assistentes sociais na saúde" o qual define, entre outras ações desenvolvidas pelos assistentes sociais na área da saúde:

Enfatizar os determinantes sociais da saúde dos usuários, familiares e acompanhantes por meio das abordagens individual e/ou grupal; democratizar as informações por meio de orientações (individuais e coletivas) e /ou encaminhamentos quanto aos direitos sociais da população usuária; fortalecer os vínculos familiares, na perspectiva de incentivar o usuário e sua família a se tornarem sujeitos do processo de promoção, proteção, prevenção, recuperação e reabilitação da saúde (CFESS, 2010, p. 44-45).

Considera-se que a integralidade em saúde se configura em uma comunicação eficiente entre os níveis de atenção, de forma a cuidar do indivíduo como um todo, ou seja, ter a percepção do sujeito a partir do seu contexto socioeconômico e cultural (COTTA et al., 2007). Pressupõe-se, também que em função de desconhecimento, houve a violação do direito integral a saúde na medida em que direitos como a reabilitação profissional e a indenização pelo acidente, já conquistados pela classe trabalhadora, não foram acessados pelos sujeitos, ou foram acessados pela via mercadológica. Fato este que implicou diretamente no aspecto socioeconômico, levando em consideração a renda média dos entrevistados. 
Diante disso, ressalta-se a importância do Serviço Social atentar para esta população nos serviços de urgência/ emergência e área hospitalar. A intervenção do assistente social na perspectiva do empoderamento, fortalecimento do sujeito, individual ou coletivo, na sua relação de cidadania, de identificação (contra as opressões e discriminações) e de autonomia (FALEIROS, 2002) será de suma importância para que este tenha acesso aos seus direitos e, em caso de limitações, possa lutar pelos mesmos.

Ademais, é nítida a subordinação das Políticas Sociais aos interesses econômicos, ou seja, há uma proposta de desmantelamento dos ideais universalistas e igualitários na área dos direitos sociais, sendo estes substituídos pela exigência da focalização em populações vulneráveis e de risco social, conforme apregoado pelas agências mundiais de fomento e financiamento (UGINO; MARQUES, 2012).

Todavia, as expressões da questão social são uma especificidade dada pelo seu objeto de intervenção do assistente social (IAMAMOTO, 2003), assim, suas ações incidem diretamente na articulação de recursos necessários para viabilizar a proteção social de sujeitos ou coletivos usuários das diferentes políticas setoriais.

\section{CONSIDERAÇÕES FINAIS}

O estudo identificou que o perfil dos sujeitos envolvidos em acidentes de trânsito são jovens do sexo masculino, ocupantes de motocicletas, com vinculação ao RGPS. Devido às alterações na rotina familiar, a maioria requereu o auxílio de outra pessoa para os cuidados diários, sendo esta uma mulher.

Após a ocorrência do acidente, os sujeitos e seus familiares tiveram acesso aos seus direitos previdenciários. Contudo, evidenciou-se um desconhecimento acerca de outros direitos sociais por parte de alguns entrevistados, bem como limitações para o acesso a serviços e recursos de saúde necessários para a reabilitação dos envolvidos.

Nessa perspectiva, compreende-se que o direito integral à saúde a estes envolvidos em acidentes de trânsito não está sendo efetivado, o que está relacionado diretamente com as intervenções do grande capital econômico, com vista a minimizar as ações do estado e desmantelar as políticas públicas.

No entanto, é de extrema relevância que no processo de trabalho no qual se inserem os trabalhadores do serviço, o conceito de integralidade seja o balizador das ações de saúde. Nesta perspectiva, destaca-se o trabalho multidisciplinar, bem como o Serv. Soc. \& Saúde, Campinas, SP v.16, n. 1 (23), p. 99-118, jan.jjun. 2017 ISSN 1676-6806 
planejamento de alta do paciente, com vistas à continuidade no tratamento nos demais serviços da Rede de Saúde e Sócio Assistencial.

Tendo em vista que o estudo evidenciou o desconhecimento acerca de direitos sociais e inviabilização no acesso a alguns serviços, a intervenção do assistente social torna-se imprescindível no cenário do sujeito envolvido em acidente de trânsito, uma vez que tem a sensibilidade de enxergar os sujeitos em sua totalidade e historicidade, levando em consideração o contexto social no qual cada um está inserido.

Sabe-se, porém, que o processo de trabalho do assistente social não é somente por ele organizado, nem exclusivamente seu, existem sim ações que podem ser qualificadas já apresentadas ao longo do texto, contudo, o assistente social, também integrante da classe trabalhadora, enfrenta dilemas e desafios diários no seu espaço de trabalho que interferem sobremaneira no planejamento e foco das ações.

Nessa perspectiva, com respaldo do Programa de Residência Multiprofissional e, tendo em vista que o serviço é referência em trauma na região, sugere-se a discussão entre profissionais e gestores sobre a possibilidade de elaboração de uma cartilha contendo informações relevantes para que o sujeito envolvido em acidente de trânsito possa ter minimamente conhecimento sobre seus direitos, bem como onde possa reivindicá-los em caso de violação dos mesmos. Assim, de forma tangível, tanto os sujeitos, como os profissionais poderão refletir continuamente sobre a importância do trabalho em equipe, o que irá qualificar o serviço prestado bem como reduzir o risco de possíveis (re) internações, uma vez que os demais serviços da rede serão acionados.

Cabe destacar que, durante o processo de coleta de dados, alguns entrevistados realizaram vários questionamentos acerca dos direitos previdenciários, o que enaltece a importância de proporcionar aos sujeitos um espaço de diálogo, construído numa relação de horizontalidade, respeito às singularidades e de valorização dos projetos de vida das pessoas.

O fato de essa temática emergir do Serviço Social reitera a importância do profissional assistente social em uma equipe de saúde que através de uma leitura crítica da realidade e com todo o seu aporte teórico metodológico contribui sobremaneira para a autonomia, o exercício da cidadania e principalmente, para a efetivação do direito integral a saúde de sujeitos envolvidos em acidentes de trânsito. 


\section{REFERÊNCIAS}

ANJOS, K. C. et al. Paciente vítima de violência no trânsito: Análise do perfil socioeconômico, características do acidente e intervenção do Serviço Social na emergência. Acta Ortopédica brasileira, nº 5, São Paulo, 2007.

Disponível em: http://dx.doi.org/10.1590/S1413-78522007000500006 Acesso em: 01 jun. 2015.

ANJOS, K. C. Implicações Sociais e Econômicas nos pacientes vítimas de acidentes com motocicletas internados no IOT-HCFMUSP. Dissertação (mestrado). Faculdade de Medicina da Universidade de São Paulo, São Paulo, 2012. Disponível em: http://www.teses.usp.br/teses/disponiveis/5/5140/tde-09012013-170224/pt-br.php. Acesso em: 10 jun. 2015.

ANTUNES, R.; POCHMANN, M.; A desconstrução do trabalho e a explosão do desemprego estrutural e da pobreza no Brasil. In: Produção de pobreza e desigualdade na América Latina. Tomo Editorial, Porto Alegre, 2007. ASCARI, R. A.; et al. Perfil epidemiológico de vítimas de acidente de trânsito. Revista de Enfermagem da Universidade de Santa Maria; no 3 p. 112-121, Santa Maria, 2013.

BRASIL, Lei no 8.213, de 24 de julho 1991. Dispõe sobre os Planos de Benefícios da Previdência Social e dá outras providências. Brasília, 1991.

BRASIL. Lei nº 6.194 de 19 de dezembro de 1974. Dispõe sobre Seguro Obrigatório de Danos Pessoais causados por veículos automotores de via terrestre, ou por sua carga, a pessoas transportadas ou não. Brasília, 1974.

BRASIL. Ministério da Saúde. Secretaria de Vigilância em Saúde. Saúde Brasil 2010: Uma análise da situação de saúde e de evidências selecionadas de impacto de ações de vigilância em saúde. Brasília: Ministério da Saúde; 2011.

BRASIL. Lei $\mathrm{n}^{\circ} 8.080$ de 19 de setembro de 1990. Dispõe sobre as condições para a promoção, proteção, e recuperação da saúde, organização e funcionamento dos serviços, Brasília, 1990.

BRAVO, M. I. S. As Políticas de Seguridade Social Saúde. In: CFESS/ CEAD.

Capacitação em Serviço Social e Política Social. Módulo III: Política Social. Brasília: UnB- CEAD/ CFESS, 2000. Rio de Janeiro, 2001.

CAIXETA, C. R. et al.; Morbidade por acidentes de transporte entre jovens de Goiânia. Revista Ciência e Saúde Coletiva. nº 4; Rio de Janeiro, 2010. 
Disponível em: http://dx.doi.org/10.1590/S1413-81232010000400021

Acesso em: 10 jun. 2015.

CFESS. Conselho Federal de Serviço Social. Parâmetros para a atuação de assistentes sociais na Política de Saúde. Série Trabalho e Projeto Profissional nas Políticas Sociais, Brasília, 2010.

CAVALCANTE, F. G.; MORITA, P. A.; HADDAD, S. R. Sequelas invisíveis dos acidentes de trânsito: o transtorno de estresse pós traumático como problema de saúde pública. Revista Ciência e Saúde Coletiva, nº 5, Rio de Janeiro, 2009.

COTTA, A et al. Pobreza, Injustiça, e desigualdade social: repensando a formação de profissionais de saúde. Revista Brasileira de Educação Médica, n. 313. Rio de Janeiro, v. 29, n. 1. 2007.

FALEIROS, V. P. Estratégias em Serviço Social. 4. ed. São Paulo: Cortez, 2002. FERREIRA, R. V.; COSTA, M. R.; MELO, D. C. S.; Planejamento Familiar: gênero e significados. Revista Textos e Contextos; n. 2, p. 387 - 397. Porto Alegre, 2014. GAVILANES, H. A.; AGUIAR, N. Patriarcado e gênero na análise sociológica do fenômeno da violência conjugal/gênero. In: SOUZA, M. F. (Org.). Desigualdades de gênero no Brasil: novas ideias e práticas antigas. Belo Horizonte: 2010.

GIL, Antônio Carlos. Métodos e técnicas de pesquisa social. - 6 ed. São Paulo: Atlas, 2008.

GOLIAS, A. R. C; CAETANO, R.; VIANA, M. M.; Caracterização e custos de acidentes de motocicleta com vítimas atendidas em regime de hospitalização no município de Paranavaí - PR no ano de 2007. Physis - Revista de Saúde Coletiva, ${ }^{\circ}$ 23; Rio de Janeiro, 2013.

IAMAMOTO, M. V. Projeto profissional, espaços ocupacionais e trabalho do assistente social na atualidade. In: CFESS-Conselho Federal de Serviço Social. Atribuições privativas do (a) assistente social. Brasília: CFESS, 2002, p. 13-50.

IAMAMOTO, M. V. O Serviço Social na Contemporaneidade: trabalho e formação profissional. São Paulo: Cortez, 2003.

IAMAMOTO, M. V. Serviço Social em tempos de Capital Fetiche: capital financeiro, trabalho e questão social. $4^{\circ}$ Ed. Cortez: São Paulo, 2010.

MARÍN-LEÓN, L. Tendências dos acidentes de trânsito em Campinas, São Paulo, Brasil: importância crescente dos motociclistas. Cadernos de Saúde Pública. 28 (1): 
39-51, jan, Rio de Janeiro, 2012. Disponível em: www.scielo.br/pdf/csp/v28n1/05.pdf. Acesso em: 25 jun. 2015.

MARTINS, R. T. Seguro DPVAT: Seguro obrigatório de veículos automotores de vias terrestres. Servanda Editora, Campinas-SP, 2009.

MARX, K. O Capital: Crítica da Economia Política. Vol. 1, tomo 1, 3 ed. São Paulo: Nova cultural, 1988.

MATTOS, R. A. de. Os sentidos da Integralidade. Algumas reflexões acerca de valores que merecem ser defendidos. In: PINHEIRO, R.; MATTOS, R. A. (org.). Os sentidos da integralidade na atenção e no cuidado à saúde. Rio de Janeiro: Universidade do Estado do Rio de Janeiro/ABRASCO; 2009.

MIOTO, R. C. T.; NOGUEIRA, V. M. R. Política Social e Serviço Social: os desafios da intervenção profissional. Katálysis. v. 16, n. esp., p. 61-71. Florianópolis, 2013. NETTO, J. P. Capitalismo Monopolista e Serviço Social. São Paulo: Cortez, 1992. NICÁCIO, F.; AMARANTE, P.; BARROS, D. Franco Basaglia em terras brasileiras: caminhantes e itinerários. In: AMARANTE, P. (org.). Arquivos de Saúde Mental e Atenção Psicossocial 2. Rio de Janeiro: NAU, 2005.

OLIVEIRA N. L. B, SOUZA, R. M. C. Motociclistas frente às demais vítimas de acidentes de trânsito no município de Maringá. Acta Scientiarum. Health Sciences Maringá, v. 26, n. 2, p. 303-310, 2008.

PALU, L. A. O custo social dos acidentes com motocicletas e sua correlação com os índices de trauma. Dissertação [mestrado] Universidade do Paraná, Curitiba, 2013. Disponível em: http://acervodigital.ufpr.br/handle/1884/29981

Acesso em 15 out 2016.

PEDEN, M. World Report on Road Traffic Injury Prevention. World Health Organization. Geneva: WHO; 2004. Disponível em:

http://apps.who.int/iris/bitstream/10665/42871/1/9241562609.pdf Acesso em: 10 set 2016.

QUINTANEIRO, T. Um toque de clássicos: Marx, Durkheim e Weber. Editora UFMG, Belo Horizonte, 2002.

RODRIGUES, J. M. Evolução da frota de automóveis e motos no Brasil: 2001 a 2011. Observatório das Metrópoles. Instituto Nacional de Ciência e Tecnologia, Rio de janeiro, 2013. Disponível em:

http://www.observatoriodasmetropoles.net/download/auto_motos2013.pdf ROUDINESCO, E. A família em desordem. Rio de Janeiro: Jorge Jarah, 2003 Serv. Soc. \& Saúde, Campinas, SP v.16, n. 1 (23), p. 99-118, jan./jun. 2017 ISSN 1676-6806 
SANTOS, A. M. R. et al. Perfil das vítimas de trauma por acidente de moto atendido em um serviço público de emergência. Caderno Saúde Pública, nº 8, Rio de janeiro, 2008. SIERRA, V. M.; VELOSO, R. S.; Família no Estado Democrático de direito: O material e o simbólico na reprodução da ordem (neo) liberal. Revista Textos \& Contextos, $\mathrm{n}^{\circ}$ 2,ago./dez; Porto Alegre, 2015.

SOUZA, H. M. Programa Saúde da Família: Revista Brasileira de Enfermagem, Brasília, v. 53, n. especial, dez. 2000.

UGINO, C. K.; MARQUES, R. M.; As Reformas previdenciárias brasileiras sob a pressão neoliberal. Revista Textos \& Contextos, jan./ Porto Alegre, 2012.

VASCONCELOS. E. A. O custo social da motocicleta no Brasil. Revista dos Transportes Públicos - ANTP. Ano 30/31; 2008. 
